\title{
FENOMENOLOGÍA
}

\section{CÁNCER DE MAMA. UNA EXPERIENCIA PERSONAL $M^{a}$ del Carmen Solano Ruiz \\ Profesora Titular. Departamento de Enfermería. Universidad de Alicante}

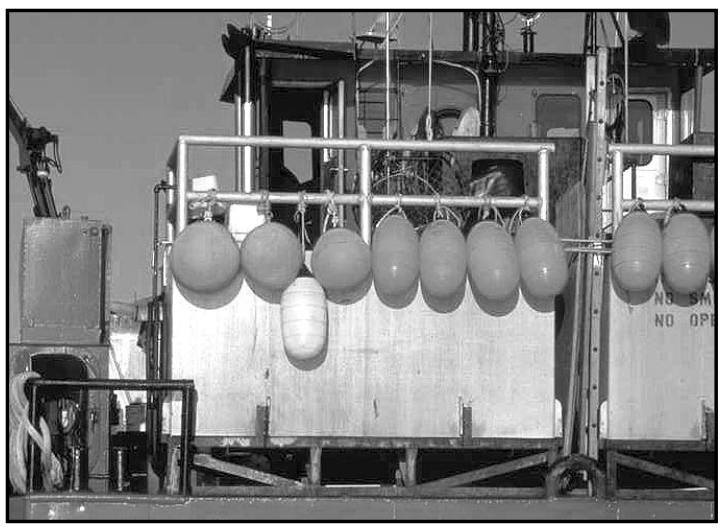

\section{BREAST CANCER. A PERSONAL EXPERIENCE}

\section{ABSTRACT}

7 he present report shows a personal history of a 35-year-old woman, diagnosed of a breast cancer 2 years earlier. It expresses her own way of living her illness and the different processes she had submitted to fight against it. At the same time, her wish for life and her continuous positive behaviour not to consider herself as "a sick woman", as well as her developing strategies to face desperate moments in her daily life.

The use of life histories as a working technique in the data gathering could help nurse professionals to discover the personal and real meaning of such an illness, to deepen into the roots of different experiences and to articulate nursing strategies and ways addressed to lessen negative feelings in order to get better evolutions within the process of an illness. At the same time, these type of reports help the main character implied - "the protagonist" - to feel very well acquainted with all those other women undertaking the same sort of process.
Key words: breast cancer, life history.

\section{RESUMEN}

7 ste relato narra la historia personal de una $\checkmark$ mujer de 35 años de edad, diagnosticada desde hace 2 años de cáncer de mama, muestra su propia vivencia de la enfermedad y los diferentes procesos a los que se debe enfrentar para poder combatirla.

Los deseos de vivir y la negación constante a sentirse enferma así como las diferentes estrategias utilizadas en los momentos de desesperación, la han acompañado en su lucha diaria.

La utilización de las historias de vida como técnica de trabajo en la recogida de datos puede ayudar a los profesionales de enfermería a descubrir el significado propio e individual de la enfermedad, conocer con profundidad la experiencia sentida y establecer así unas actuaciones de enfermería dirigidas a minimizar los sentimientos negativos que favorezcan una evolución más satisfactoria de su enfermedad. Así mismo con este tipo de relatos, la protagonista trata de solidarizarse con todas aquellas mujeres que están atravesando por el mismo proceso.

Palabras clave: cáncer de mama, historia de vida.

\section{INTRODUCCIÓN}

A pesar de encontrarnos en pleno siglo XXI, al cáncer se le considera como una enfermedad grave y la primera causa de muertes en España.

Dentro del grupo de las enfermedades oncológicas, el cáncer de mama es el tumor que más afecta a la población de mujeres de los países occidentales.

En los últimos años y como consecuencia de los importantes avances diagnósticos y terapéuticos, junto con las campañas de detección precoz, 
la mortalidad en mujeres afectadas por esta enfermedad se ha visto disminuida. Este mismo hecho, a su vez ha provocado un incremento de forma paulatina en la detección y el diagnóstico de mujeres aquejadas por dicha patología. Se estima que 8 de cada 100 mujeres desarrollarán un cáncer de mama antes de los 75 años de edad (López-Albente et al, 2003).

En nuestra sociedad, la mujer es considerada como pilar básico en la estructura familiar y social (Siles, 2005) es por tanto, que el diagnóstico de esta enfermedad específica de la mujer, implica una ruptura en la vida diaria, no sólo a nivel personal si no también a nivel familiar y social, apareciendo así una nueva situación que requiere la necesidad de crear importantes reajustes a todos estos niveles.

El cáncer de mama supone una vivencia muy profunda, cargada de sentimientos: la negatividad hacia la propia enfermedad, la alteración de la propia imagen corporal, la angustia, la desesperación y la incertidumbre son algunas situaciones por las que la persona que la padece deberá afrontar creando estrategias apropiadas a cada proceso (Suárez, 2002).

El objetivo de este estudio es manifestar la experiencia vivida y sentida por una mujer de 35 años de edad diagnosticada de cáncer de mama y enfermedad de Paget, narrada en primera persona.

La protagonista de este relato consideramos que merece especial mención por su fortaleza de ánimo y valentía, por los vigorosos deseos de vivir, por la reacción de lucha ante la enfermedad y por su negación constante a sentirse enferma.

Para conocer su relato, es necesario utilizar un instrumento adecuado como es la historia oral. Este tipo de instrumento nos permite un conocimiento global de la persona a estudiar, así cómo la posibilidad de conocer el carácter subjetivo, personal e íntimo de sus memorias y opiniones, captando de esta manera todas sus dimensiones, tanto su significado como la interpretación que ésta tiene con respecto al proceso que está experimentando. (Siles, 1999; Amezcua y Hueso, 2004).

A través de una entrevista en profundidad (Vallés, 2000) se obtuvo el relato que posteriormente paso a exponer de forma resumida, sin alterar el contenido del mismo.
La protagonista aceptó su colaboración y en todo momento se sintió cómoda con el desarrollo de la misma. La entrevista se grabó en una cinta audio y la duración de la misma fue de 90 minutos, posteriormente se transcribió íntegramente para proceder al análisis del contenido de forma cualitativa, encontrándose diferentes aspectos a destacar que han sido agrupados en diversas temáticas siguiendo un orden cronológico.

Como conclusión de este estudio, considero que la protagonista de esta historia nos muestra una lección de coraje y de gran capacidad de adaptación en los momentos críticos y que con su historia no sólo es capaz de brindar su apoyo y su valor a todas las mujeres que están atravesando el duro momento de la enfermedad, si no que además a los profesionales sanitarios nos puede ayudar a reconocer el proceso individual y subjetivo por el que cada persona afronta esta situación. No debemos olvidar que tratamos a las personas y no exclusivamente el diagnóstico médico que se le atribuya, y que, por supuesto, debido a la gran complejidad del ser humano ante un mismo evento pueden aparecer múltiples y variadas respuestas.

\section{BIBLIOGRAFÍA}

- Amezcua, M y Hueso, C (2004). Cómo elaborar un relato biográfico. Archivos de la memoria 2004; Disponible en : http://www.index_f.com/memoria/metodologia.php.Consulta 8 julio 2005

- López-Albente, G; Pollán, M; Aragonés, N; Pérez-Gómez (2003). Informe sobre la salud de los españoles. Cáncer. Centro Nacional de Epidemiología. Área de Epidemiología Ambiental y Cáncer. Disponible en: http://193.146.50.130/cancer/cancer1.htm

- Siles, J. (1999). Historia de Enfermería. Editorial Aguaclara.

- Siles, J; Solano, MC (2005). Estructuras sociales, división sexual del trabajo y enfoques metodológicos: la estructura familiar y la función sociosanitaria de la mujer. En prensa: Investigación y Educación en enfermería. Universidad de Antioquia. Colombia

- Suárez, M (2002). Diagnóstico cáncer: mi lucha por la vida. Ed Galaxia Gutemberg/ Circulo de lectores. Barcelona

- Vallés, M (2000). Técnicas de conversación narración: las entrevistas en profundidad. En: Técnicas cualitativas de investigación Social. Edt Síntesis. Madrid

\section{RELATO}

\section{Infancia- Juventud.}

Nací el 23 de Octubre de 1969 en Elche y he vivido siempre aquí. Tengo dos hermanos, somos tres en total, yo soy la mayor nos llevamos 5 años 
cada uno, mi hermana cinco menos que yo y mi hermano diez. Yo siempre me he considerado muy buena estudiante, he sacado buenas notas lo que pasa es que sabes que vienes de una familia humilde y eso de que nunca te han inculcado algo de estudiar, si estudiaba era porque a mí me gustaba. Me metí en formación profesional hice jardines de infancia pero luego tampoco tenía salidas. Encontré una oficina que no tenía nada que ver con lo que yo había estudiado, pero como también me gustaba empecé como de secretaria.

Con 14 años una amiga y yo nos presentamos a la belleza del barrio, yo estaba un poco llamativa tenía el pelo rubio muy largo rizado, ojos claros, me sentía bien. Soy un poco tímida, cortada, un poco prudente y eso de hablar yo no soy muy parlanchina sobre todo al principio cuando no conoces.

A los 17 años conocí al que hoy es mi marido y cinco años más tarde nos casamos. Estuvimos cuatro años sin tener hijos, el primero lo tuve en el 97, ahora va a cumplir 8 años. Siempre decíamos que queríamos tener tres o cuatro y tenerlos seguidos, yo siempre procuraba encontrarme recuperada y bien y cuando ya me veía con fuerzas "ala" por el otro, así que, al año y medio o así me quedé embarazada de otro niño. Todo muy bien los embarazos fenomenal haciendo deporte y con una vida normal, pero cómo yo quería una nena fui a por ella.

\section{Enfermedad}

Cuando di a luz a la niña, le di cuatro meses pecho que me costó muchísimo lo pasé fatal había un pecho que no le gustaba, me hizo unas grietas. Al poco de dejar de darle el pecho noté que me supuraba el pezón, viendo que no mejoraba me fui al hospital por que como tenía antecedentes de fibroadenomas y mastopatía fibroquística, a los 18 años me quitaron un fibroadenoma y al año y medio me quitaron otro, tenía revisiones periódicas por que también tenía antecedentes de una tía que falleció con 33 años de cáncer de mama, y claro eso me marcó mucho.

En el hospital me hicieron un análisis para ver si lo que salía era una infección, me dijeron que no y estaban ahí un poco por que eso fue en junio, luego en julio me dieron los resultados de la mamografía que me hicieron también en junio y parece que me dijeron que se veía algo raro que había unas microcalcificaciones que no sabían que tenían que hablarlo entre ellos en el consejo de mama.

Como en el mes de Agosto no hay consulta me citaron en Septiembre para decirme que sí que después de estudiarlo y tal que me iban a operar pero que no le dieron urgencia tampoco y que me iban hacer a la vez una biopsia del pezón por que me seguía supurando. Tampoco esperarían que fuese una cosa tan agresiva lo que yo tenía pues desde junio que fui que no tenía nada en el pecho por que las microcalcificaciones no se nota nada en la autoexploración, sólo tenía lo del pezón y en noviembre que me hicieron lo de la biopsia me notaba ahí unas durezas considerablemente importantes.

Bueno un poco desesperada para ver los resultados que salían y a las dos semanas después me dieron los resultados que habían sido patológicos... que vamos que tenía los dos: la enfermedad de Paget y que tenía microcalcificaciones patológicas y que tenía que intervenir y quitarme la mama y los ganglios de la axila.

Bueno ahí ya un shock bastante traumático, en ese momento tampoco piensas así.., piensas que vas a tener un proceso ahí de pasarlo mal pero que lo primero que piensas es en luchar. La verdad es que hasta que te operan pasan dos semanas y piensas incluso en operarte en una clínica privada. Son las dos semanas más largas de mi vida, tienes los nervios en el estómago, no puedes comer, pero cuando llega el momento de la intervención y te operan y te quitan el pecho para mí fue cuando te quitan una tonelada de encima te quedas descansando.

Después estás ahí que no sabes, también el médico me dijo: "Tranquila que esto está muy localizado" no sé si era para que pasara bien la Navidad que era Navidad o por que el hombre...no lo sé, no lo sé por que yo si que en ese momento estás más receptiva de todo, te fijas en lo que puedan hablar un poco por ahí, si están un poco apartados te fijas en todo te crees te haces montañas, por lo menos yo, de un grano de arena, te fijas si te tratan mejor, si te tratan peor, siempre estás buscando tú, más que lo que hagan es lo que tu quieras un poco analizar, lo que estás viendo es.. por 
que luego cuando pasa el tiempo te das cuenta que a lo mejor de algunas cosas sí tenían razón pero de otras son castillos que te has hecho y entonces Francisco siempre me lo dice que nunca hay que, siempre hay que ser lo más optimista, no hacer un castillo antes de tener las cosas, no hacer un problema antes de que aparezca, y si realmente aparece buscar una solución y dársela.

\section{Apoyo emocional}

Yo sólo cuento con el apoyo de mi marido, en lo más íntimo y en lo más doloroso. El es bastante fuerte, a lo mejor cuando él esté a solas pero él no me demuestra que esté mal, sabes que las cosas se van llevando y ...

\section{Imagen externa}

Ahora otra vez se me va a caer el pelo, llega el verano, me apetece hacer gimnasia, aunque en mi casa puedo me gusta mucho nadar y entonces me planteo que hago me voy con el pañuelo, llega un momento que...yo siempre he intentando guardar la máxima discreción que se entere la menos gente posible no estar de cara a la gente con mal aspecto, si se enteran no me importa, pero no quiero ir contando ...por que no me digan otra vez...Así que pienso cuando vaya a la playa me llevo la peluca, pues no yo voy a estar cómoda y mis hijos y mi marido y los amigos más cercanos lo saben pues...lo único que si me para es los niños hay algunos que no lo saben no comprenden y no sabes si van a crear rechazo o impactarles y eso es lo que me frena a mí de lo mejor de no llevar la peluca. Yo he tratado explicárselos a mi hijo con naturalidad.

\section{Personal sanitario}

En el hospital con las enfermeras muy bien, tengo mal recuerdo del ginecólogo pues pienso que no le dio la importancia que realmente tenía por que cuando recibes la anatomía patológica y ves que tienes un tumor de $7.5 \mathrm{~cm}$, la enfermedad de Paget, afectación de ganglios linfáticos 9 de 12, aunque cuando leo el informe en ese momento no entendía nada, entiendo que es un nivel 3,3 y el ginecólogo no te dice nada sólo que tienes que ir a oncología. Aunque a veces prefieres no tener demasiada información aunque a mí me gusta saber las cosas, pero en ese momento necesitas algo más. Por que cuando fueron a curarme a casa me dijeron que estuviera tranquila que aunque fuera algo malo en estos momentos hay muchos tratamientos que hoy en día hay muchos adelantos, yo necesitaba escuchar eso... que hay posibles soluciones.

\section{Tratamientos}

El oncólogo me explico todo y los diferentes tratamientos y que íbamos a probar con uno el que él pensaba que era el más eficaz, esperar resultados y paciencia, pero que la quimioterapia la tienes que pasar.

\section{Recomendaciones}

Cada persona reaccionamos de una manera. La reacción tras el diagnóstico es inevitable hay un periodo de tiempo que mientras se asimila y te haces a la idea tienes que pensar que hay que evitar hacer un problema antes de que haya el problema, y si el problema está ahí, que soluciones hay. Tienes que tener esperanza, ser positiva, estar distraída el máximo tiempo posible, evitar el pensar y pensar y darle vueltas.

Son diferentes etapas que tienes que pasar, al principio dices uf! Se me va a caer el pelo pero una vez que se te ha caído y te has adaptado pues quiero decir que yo lo que hacía es siempre estar cómoda yo, intentando pasar lo más desapercibida posible, ir bien arreglada lo tenía como norma ir pintada yo tenía como norma arreglarme bien, antes de que se me cayera el pelo me busqué una peluca similar a mi pelo. Hacer una vida lo más normal posible, no estar pendiente por si te pones mala o no, no estar esperando a que te vas a poner mal y si te pones mal tener la posibilidad de marcharte. 